\title{
Influence of Personality, Shopper type and Social Support on the Consumers' Need for Status and Continuance Intention in E-commerce
}

\author{
Ifeoma Adaji \\ University of Saskatchewan \\ Saskatchewan, Canada \\ Ifeoma.adaji@usask.ca
}

\author{
Kiemute Oyibo \\ University of Saskatchewan \\ Saskatchewan, Canada \\ Kiemute.oyibo@usask.ca
}

\author{
Julita Vassileva \\ University of Saskatchewan \\ Saskatchewan, Canada \\ jiv@cs.usask.ca
}

\begin{abstract}
With the increase in the number of companies doing business online, simply selling their products online will not help an e-business make new clients and maintain existing ones. Businesses have to implement strategies that will make their business attractive to new clients while maintaining existing customers. The use of personalization has been suggested as an e-commerce strategy that businesses can use to attract and retain clients. To contribute to ongoing research in this area, we explore the use of personality, shopper type, social support and need for status in ecommerce personalization and their influence on the continuance intention of e-commerce shoppers. Using a sample size of 226 e-commerce shoppers, we develop and test a global research model using partial least-squares structural equation modelling (PLS-SEM) analysis. In addition, we carried out multi-group analysis between males and females to determine if there are any significant differences between both groups. Our results show that personality, shopper type, social support and need for status explain almost $60 \%$ of the variance in the continuance intention of consumers to shop online. In addition, shopper type has the strongest effect on continuance intention compared to personality, need for status and social support. Furthermore, the personality of males significantly influenced their continuance intention of shopping online, while this was insignificant for females. These findings suggest possible design guidelines in developing personalized e-commerce shopping experience for consumers.
\end{abstract}

Personality, Shopper Type, Social Support, Need for Status.

\section{INTRODUCTION}

With many companies now having an online presence, the competition to retain clients and make new ones has become fiercer. Simply selling products or services online is no longer enough for businesses to distinguish themselves among their competitors. Forrester Research ${ }^{1}$, a leading research company, projects that in 2018, major companies will cut down significantly on advertisements because customers avoid ads. They project that companies will likely spend more on improving customer's online experience by creating a more personalized shopping experience for the customers. Personalization has been identified as a means through which e-businesses can increase their consumers' lifetime value [36]. Several attempts have been made in the past to improve personalization in e-commerce using the

${ }^{1}$ https://go.forrester.com/research/predictions/ personality type of the shoppers [11], their shopping motivation and behaviour [30], their need for social support [1] and their need for status [15].

In e-commerce, the personality type of users has been used to create a more personalized website design and features for e-shoppers [11], thus we adopted personality in this study. Identifying a customer's shopper type has also been suggested as a means of personalizing consumers' shopping experience. The shopper type classifies consumers with similar shopping decision-making process and motivation together. Research has shown that by identifying consumers' shopper type, e-commerce companies can effectively tailor products and services to the various segments of customers and thus create a more personalized shopping experience for the consumers [30]. Social support has been shown to have an influence on continuance intention in e-commerce [1], which suggests that it can be used to create a more 
personalized shopping experience for consumers. Need for status describes how people are influenced by the need to appear prestigious, worthy of envy, or admirable [12]. It influences people's perceptions of product prices, their purchase decision and continuance intention of patronizing a brand [15].

In the current study, we contribute to ongoing research in the area of e-commerce personalization by exploring the effect of personality, shopper type, social support and need for status on the continuance intention of e-shoppers. In particular, we want to identify which factor(s) has the greatest influence on the continuance intention of ecommerce shoppers. We hypothesize that if these factors influence continuance intention, personalization based on these factors will likely lead to a more engaging and satisfactory shopping experience for the consumer.

Using a sample size of 226 e-commerce shoppers, we developed a global research model using partial least-squares structural equation modelling (PLSSEM). Our results show that personality, shopper type, social support and need for status explain almost $60 \%$ of the variance in the continuance intention of users to shop online. This suggests that personality, shopper type, social support and need for status are good predictors of e-commerce continuance intention. In addition, shopper type has the strongest effect on continuance intention compared to personality, need for status and social support. This suggests the significance of identifying the shopping motivation and behaviour of consumers in e-commerce. In addition, we carried out multi-group analysis between males and females to determine if there were any significant differences between both genders. Our results suggest that the personality of males significantly influenced their continuance intention of shopping online, while this was insignificant for females. These findings suggest the possibility of creating a personalized shopping experience for online consumers using gender, personality, shopper type, social support and need for status.

\section{RELATED WORK}

\subsection{Personality}

A person's personality are the notable features, such as behaviour and emotional pattern, of the individual in various social and personal context. People of the same personality typically behave in a similar way and have similar habits [24]. The use of personality in personalization has been adopted in various domains including e-commerce. Cunningham et al. [11] developed a framework to match consumers' personality traits to e-commerce website design. The authors suggest that because consumers have different personality types, and the different personality types have varying opinions on how they perceive the e-commerce environment and make decisions, it is important to consider personalities and preferences when designing e-commerce websites. Barkhi and Wallace [4] also explored the influence of consumers' personality on the design and features of e-commerce platforms. They concluded that the features of an e-commerce website can be tailored to users based on their personalities.

There are several personality taxonomies that group people with similar traits together, with people in each group having a high tendency to behave in a particular way under certain situations. One of such models is the Big Five (also referred to as the Five-Factor Model) which describes a person's personality using five factors: openness to experience, conscientiousness, extraversion, agreeableness and neuroticism [14]. In this paper, we use this model because it is commonly used in various domains including consumer studies [19]. Based on the model, people with extraversion traits are talkative, energetic and assertive while those with agreeableness trait are cooperative, goodnatured and can be trusted. A high level of conscientiousness describes people who are dependable, responsible and orderly, while low neuroticism characterizes people who are calm and are not easily upset. People with personality trait openness to experience, are known to be imaginative, independent-minded and intellectual [20].

\subsection{Shopper Type}

Classifying shoppers according to their shopping motivation and behaviour has been suggested as a way to help businesses effectively tailor products and services to the various segments of customers [30]. It also helps businesses to better understand the attitude of their customers and what they look out for in their shopping decision-making process [21]. Several typologies of online shoppers have been developed in the past. Kau et al. [21] classified online shoppers into six categories based on the motivation and concerns of online shoppers and their information seeking patterns. Rohm and Swaminathan [30] identified shopper types based on the motivations of shoppers and proposed four categories: convenience shoppers, variety seekers, balanced buyers and store-oriented shoppers. According to the authors, the convenience shoppers are motivated by online shopping convenience. Shoppers in this category do not typically seek immediate possession of their products. The variety seekers are more interested in seeking variety of products across various retailers and brands. The balanced buyers are motivated by the need to seek information online just like the variety seeker. However, the balanced 


\section{Ifeoma Adaji • Kiemute Oyibo • Julita Vassileva}

buyers plan their shopping ahead unlike the variety seekers. The store-oriented shopper wants immediate possession of goods purchased and are more inclined to social interaction. Shoppers in this category prefer the feel of a physical store to an online marketplace. We used this typology in our study because it focuses on online shopping behaviour and because the four categories identified by this typology are similar to that of other researchers such as [21] and [25].

\subsection{Perceived Social Support}

Social support describes factors that influence users by leveraging social influence from their social circles [26]. Adaji and Vassileva [1] suggest, in their study of Amazon shoppers, that social support positively influences the perceived effectiveness of an e-business, and the perceived effectiveness influences the continuance intention of e-commerce shoppers. The authors concluded that e-businesses should put strategies in place to encourage social support. In their study of online shoppers, Liang et al. [23] concluded that social support and relationship quality influence the continuance intention of users in social commerce. Various taxonomies of social support exist. In this study, we adopted that of Zimet [35]. The authors measure social support from three sources: family, significant other and friends. We adopted this classification of social support because research has shown that people see shopping as a social activity and make purchasing decisions based on their social circle which includes family, friends and their significant other [10].

\subsection{Need for Status}

Some consumers are motivated by the need to appear prestigious, worthy of envy, or admirable; this is referred to the need for status [12]. Consumers who are status conscious tend to buy luxury products to satisfy their need for status irrespective of their income or current need [7]. Need for status is not exclusive to wealthy or high income consumers, rather, it occurs in all communities of the world where the prestige of a product is measured by the social advantage its purchase offers [12]. The consumer's need for status is an important factor in consumer studies because it influences how sensitive people are to product prices, their purchase decision and their desire to continue patronizing particular brands [15]. Understanding how this influences their purchase decision could enable e-businesses to create a more personalized experience for the shopper.

Clark et al. [9] explored the need for status among retail consumers. Their study revealed that status seeking shoppers typically conform to group norms, pay attention to social comparison information and do not usually seek the opinion of others when making a purchase decision. In Chan's study of need for status and consumer's repurchase intention [7], he concluded that need for status positively influences consumers' repurchase intention of luxury brands. Though need for status has been explored in the brick and mortar retail industry, not much has been done in e-commerce. We therefore explore the need for status in ecommerce.

We hypothesize that using the personality of an ecommerce user in addition to their shopper type, need for social support and need for status, could lead to a more personalized shopping experience for them. Therefore, it is imperative to explore if these factors have any influence on the shopper's continuance of shopping online.

\section{RESEARCH DESIGN AND METHODOLOGY}

In order to determine which of the factors described above has the most influence on e-consumers' continuance intention, we developed a hypothetical path model described in figure 1 using five constructs and nine hypotheses. We used previously validated scales for all constructs. These are described in the following section.

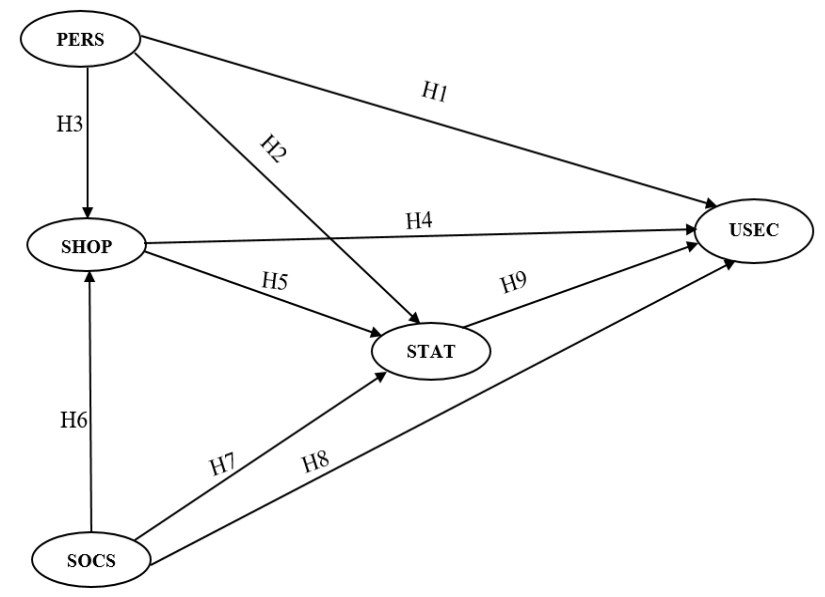

Figure 1. Research model. All paths assumed positive. PERS = Personality, SHOP = Shopper type, SOCS = Social support, STAT $=$ Need for status, USEC $=$ Continuance intention

\subsection{Description of Constructs and Hypothesis Development}

\section{Personality.}

Because personality influences technology acceptance in e-commerce [34], we hypothesize that personality will also influence e-commerce continuance intention of online shoppers. We thus propose the following hypothesis: 


\section{Ifeoma Adaji • Kiemute Oyibo • Julita Vassileva}

$\mathrm{H} 1$ : The personality of online shoppers influences their continuance intention of ecommerce.

The Big Five personality traits have also been shown to have a relationship with status. According to Bucciol et al. [6], peoples' need for status is influenced by all Big Five personality traits in socioeconomic settings. We hypothesize that a similar

A person's personality is related to his/her attitude and behaviour [14]. Since personality is not a physical characteristic, one's personality can only be inferred by their attitude and behaviour in a given context [2]. Therefore, a person's personality will likely influence how they behave, for example their shopping pattern, in a given context, such as e-commerce. We thus hypothesize that personality influences an individual's shopper type since shopper type is based on behaviour. We propose the following hypothesis:

H3: The personality of an online shopper positively influences their shopper type

\section{Shopper Type.}

Classifying shoppers according to their shopping behaviour has been shown to help businesses effectively personalize products and services to the various segments of customers [30]. Since personalization has been shown to increase customer retention [36], we hypothesize that classifying shoppers according to their shopper types can influence their e-commerce continuance intention. We therefore propose the following hypothesis:

H4: Shopper type influences e-commerce shoppers' continuance intention.

Research shows that the shopping behaviour of consumers, such as searching for particular brands or searching for products that cost certain amounts, influence their need for status [13]. Since a consumer's shopper type is a classification of the individual based on his/her shopping behaviour, we hypothesize that shopper type influences a consumer's need for status and propose the following hypothesis:

H5: The shopper type of an individual influences their need for status.

\section{Social Support.}

Social support strategies leverage social influence to bring about the desired behaviour change in people [26]. Since social support strategies influence behaviour change, and because shopper types are derived from the shopping behaviour and motivation of consumers [21], we hypothesize that social support will positively influence the shopper relationship could exist in e-commerce, thus, we propose the following hypothesis:

H2: The personality of online shoppers positively influences their need for status in e-commerce.

type of e-commerce shoppers. The shopping behaviour and motivation of consumers has been shown to influence the purchase decision of consumers. Materialistic shoppers, for example, typically purchase products that confer status [16]. Thus, we hypothesize that the shopper type of the consumer will influence their need for status. We propose the following hypotheses:

H6: Social support positively impacts shopper types.

H7: Social support positively influences need for status.

Social support strategies have been found to influence consumers' future shopping intentions [23]. We therefore hypothesize that social support will have a positive impact on the future purchase intention of shoppers. Based on this, we propose the following:

H8: Social support positively influences continuance intention of e-commerce shoppers.

\section{Need for Status.}

The consumer's need for status influences how sensitive people are to product prices, their purchase decision and their desire to continue patronizing particular brands [15]. We therefore hypothesize that in e-commerce, need for status will influence the continuance intention of shoppers. Thus, we propose the following hypothesis:

H9: Need for status positively affects the continuance intention of e-commerce shoppers

\subsection{Measurement Model}

We adopted previously validated scales in measuring the five constructs shown in figure 1. Personality was measured using Gosling et al.'s scale [17] which is made up of five constructs (openness, conscientiousness, extraversion, agreeableness and neuroticism) with two items per construct. Shopper type was measured using the scale of Rohm and Swaminathan [30] which consists of four constructs (convenience shoppers, variety seekers, balanced buyers and storeoriented shoppers) with five items per construct. Social support was measured using the scale of Zimet et al. [35] which is made up of three constructs (family, significant other and friends) and 
four items per construct. Need for status was measured using Eastman et al.'s scale [12] which consists of four items, while continuance intention was measured using the scale of Bhattacherjee [5] with three items. All items were measured on a 7point Likert scale $(1=$ strongly disagree, $7=$ strongly agree).

We adopted a hierarchical component model for the constructs personality, shopper type and social support. This approach is recommended when a construct has higher and lower level components or constructs [18]. In our model, personality construct has five lower level constructs: openness, conscientiousness, extraversion, agreeableness and neuroticism. Therefore, personality was our higher-order component and the five personality types were the lower-order components. Similarly, shopper type was a higher-order component while convenience shoppers, variety seekers, balanced buyers and store-oriented shoppers were lowerorder components. In addition, social support was a higher-order component while family, significant other and friends were its lower-order components.

\subsection{Participants}

We recruited 226 participants for this study through Amazon's Mechanical Turk and online social media platforms and news boards. Participation was voluntary and was approved by the ethics board of our university. The demographics of the participants are shown in table 1 in percentage.

Table 1. Demographics of participants

\begin{tabular}{|c|c|c|}
\hline Demographics & Value & Frequency (\%) \\
\hline \multirow[t]{3}{*}{ Age } & $\begin{array}{l}\text { Less than } 30 \\
\text { years }\end{array}$ & $55 \%$ \\
\hline & $\begin{array}{l}\text { Between } 30 \text { and } \\
49\end{array}$ & $40 \%$ \\
\hline & Over 50 & $5 \%$ \\
\hline \multirow[t]{2}{*}{ Gender } & Female & $44 \%$ \\
\hline & Male & $56 \%$ \\
\hline \multirow{3}{*}{$\begin{array}{l}\text { Household } \\
\text { size }\end{array}$} & 1 to 3 people & $63 \%$ \\
\hline & 4 to 5 people & $34 \%$ \\
\hline & 6 or more people & $4 \%$ \\
\hline \multirow[t]{3}{*}{$\begin{array}{l}\text { Household } \\
\text { income }\end{array}$} & $\begin{array}{l}\text { Less than } \\
\text { US } \$ 30,000\end{array}$ & $40 \%$ \\
\hline & $\begin{array}{l}\text { Between US\$ } \\
30,000 \text { and } \\
75,000\end{array}$ & $42 \%$ \\
\hline & $\begin{array}{l}\text { Above US\$ } \\
75,000\end{array}$ & $18 \%$ \\
\hline \multirow{4}{*}{$\begin{array}{l}\text { Continent of } \\
\text { origin }\end{array}$} & Europe & $8 \%$ \\
\hline & Asia & $35 \%$ \\
\hline & North America & $48 \%$ \\
\hline & Others & $9 \%$ \\
\hline
\end{tabular}

\section{DATA ANALYSIS AND RESULTS}

Analysis of our data was done using Partial Least Squares Structural Equation Modelling (PLS-SEM) with the aid of the SmartPLS tool. The following section shows the validation of the global measurement and structural models used and the results of our analysis.

\subsection{Evaluation of global measurement model}

Before completing the examination of the structural model, it is imperative to determine the reliability and validity of the constructs used and the relationships between indicators and constructs [33]. As suggested by Wong [33], we checked for indicator reliability, internal consistency reliability, convergent validity and discriminant validity.

Indicator reliability was carried out to ascertain how much variation in an item was explained by the construct. As suggested by [18], the few indicators that did not meet the minimum threshold of 0.7 were excluded from the structural model.

Composite reliability has been suggested as a replacement for Cronbach's alpha in measuring internal consistency reliability because Cronbach's alpha is sensitive to the number of items in the scale [18]. We therefore used composite reliability in this study. Composite reliability validity was established since the composite reliability values for all constructs were higher than the acceptable threshold of 0.60 to 0.70 in exploratory research [18]. Table 2 shows the composite reliability for the five constructs.

Convergent validity is a measure of the degree by which two measures of a construct are related and can be computed using the Average Variance Extracted (AVE) [18]. As shown in table 2, convergent validity is confirmed since all AVE values are greater than 0.5 , the minimum acceptable threshold [18].

Table 2. Composite reliability and AVE of the constructs used in our model

\begin{tabular}{|ccc|}
\hline Constructs & $\begin{array}{c}\text { Composite } \\
\text { Reliability }\end{array}$ & $\begin{array}{c}\text { Average Variance } \\
\text { Extracted (AVE) }\end{array}$ \\
\hline Personality & 0.878 & 0.643 \\
\hline Need for status & 0.951 & 0.829 \\
\hline Shopper type & 0.875 & 0.540 \\
\hline Social support & 0.927 & 0.517 \\
\hline $\begin{array}{c}\text { Continuance use } \\
\text { intention }\end{array}$ & 0.989 & 0.710 \\
\hline
\end{tabular}

Discriminant validity is a measure of how unique a construct is and how much it differs from other constructs in a structural model [18]. It is calculated by computing the square root of AVE for each construct. Discriminant validity is well established as the square root of AVE for each construct is greater than its correlation with any other construct. 


\subsection{Structural Model}

Having established the reliability and validity of the constructs, we proceed to examine the structural model, in particular, the coefficients of determination ( $R^{2}$ values) as well as the level and significance of the path coefficients. Figure 2 shows the path coefficients between the constructs, which explain the effect of the exogenous variables on the endogenous variables. In addition, the number of asterisks represents the significance of each direct effect. The number of asterisks ranges from 1 to 4 which corresponds with the p-value of $<0.05,<0.01,<0.001$ and $<0.0001$ respectively.

The result of our analysis shows that personality, shopper type, need for status and social support explain almost $60 \%$ of the variance in continuance intention of e-commerce shoppers. A coefficient of determination $\left(R^{2}\right)$ value of $\angle 0.30$ is considered low, while $0.30<R^{2}<0.60$ is moderate, and $\mathrm{R}^{2}>0.60$ is regarded as high [31]. Thus personality, shopper type, need for status and social support are high predictors of continuance intention in e-commerce. Of these constructs, shopper type has the highest effect on continuance intention, while social support's effect is not significant. Personality, shopper type and social support explain $40 \%$ of the variance in need for status, with shopper type having the highest effect and social support having the least effect. Thus, personality and shopper type are good predictors of need for status of e-commerce shoppers.

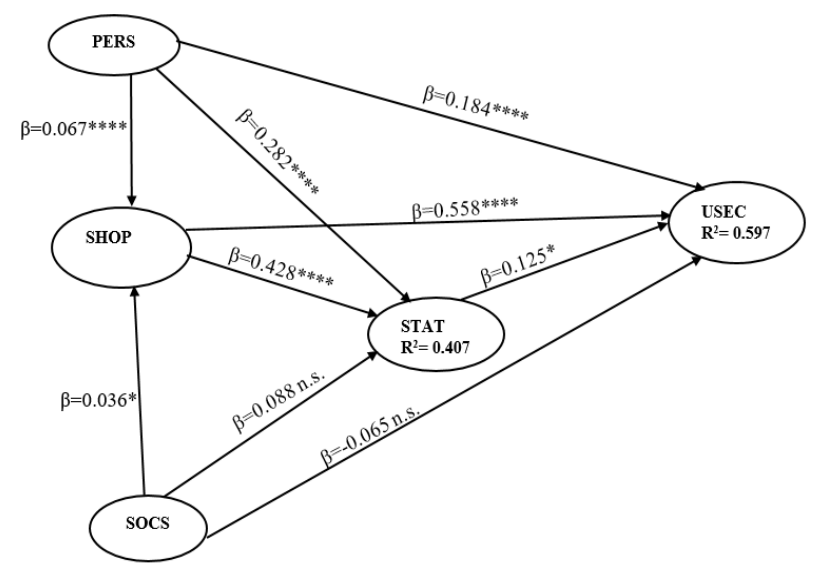

Figure 2. Structural model showing the coefficients of determination, path coefficients and significance of path effect. $P E R S=$ personality, $S H O P=$ shopper type,

SOCS $=$ Social support, STAT $=$ Need for status, USEC

$=$ Continuance intention. .. s. $=$ Not significant

\subsection{Structural Path Significance, Total Effects and Effect Sizes}

In order to determine how significant the path between constructs are, we computed the T-value for significance testing as recommended by [33]. All paths were significant except SOCS->USEC and
SOCS->STAT. Researchers suggest that the path significance is not enough to ascertain the degree of the effect an exogenous variable has on an endogenous variable and suggest the use of total effect and effect size in addition to path significance [8]. The effect size measures how much an exogenous variable contributes to an endogenous variable, it computes the strength of the relationship between constructs [33]. We adopted effect sizes of $<0.02,<0.15$ and $<0.35$ to indicate small, medium and large effect respectively based on the recommendation of [21]. The effect size between all constructs range from medium to large except for SOCS->STAT and SOCS $\rightarrow$ USEC. We did not include the table to show this due to space constraints.

\subsection{Verification of Hypotheses}

Using the path coefficient in figure 2, the strength of the path significance as described in section 4.3 and the total effect and effect sizes also described in section 4.3, we concluded that all hypotheses are valid except for $\mathrm{H} 3, \mathrm{H} 6, \mathrm{H} 7$ and $\mathrm{H} 8$. Although the path coefficients of $\mathrm{H} 3$ (PERS->SHOP) and H6 (SOCS->SHOP) are significant at $p<0.0001$ for both paths, the size of the path coefficient is considered too small to demonstrate its significance. Literature recommends at least 0.20 [33] or 0.10 [28]. We thus conclude that $\mathrm{H} 3$ and $\mathrm{H} 6$ are not validated. Similarly, H7 (SOCS->STAT) and H8 (SOCS->USEC) have low path coefficients. In addition, both paths are insignificant at $p=0.084$ and 0.120 respectively as shown in figure 2 . Furthermore, their effect sizes are small at 0.012 and 0.009 respectively. $\mathrm{H} 7$ and $\mathrm{H} 8$ are therefore not validated.

\section{DISCUSSION}

In this paper, we sought out to investigate the influence of personality, shopper type, need for status and social support on shoppers' continuance intention in e-commerce. We developed and evaluated a hypothetical path model using PLSSEM.

One significant finding is that personality, shopper type and need for status significantly explain almost $60 \%$ of the variance in the continuance intention of e-commerce shoppers. This shows that the continuance intention of shoppers can be predicted by their personality, shopper type and need for status. Of these factors, shopper type has the greatest influence on continuance intention. Shopper type classifies consumers based on their motivation and shopping behaviour [30], [21]. This result suggests that understanding the shopping motivation and behaviour of users can be used to influence the consumers to continue shopping online. This also suggests that shopper type can be 


\section{Ifeoma Adaji • Kiemute Oyibo • Julita Vassileva}

a valid criterion for personalization in e-commerce. Personalization in e-commerce is essential as it could increase the consumers' lifetime value [36] to the e-business.

Another compelling finding is that shopper type also significantly influences the need for status among consumers, and along with personality, it accounts for $40 \%$ of the variance of need for status among shoppers. This result shows that the personality of an individual and their shopper type has an influence on their need to appear prestigious irrespective of their income or wealth. Although the need for status is used in the context of brick and mortar retail shopping, the result from this study suggests that it can play a useful role in studying e-commerce shoppers, as it significantly influences the continuance intention of e-shoppers. This is in line with the conclusions of [7] who suggest that shoppers who are status conscious tend to buy luxury products to satisfy their need for status irrespective of their income or current need, thus will likely continue shopping with a merchant if this need is met.

To determine if there were any changes in the results based on gender, we carried out multi-group analysis of females and males.

\subsection{Multi-Group Analysis of Females and Males}

To ascertain if the results described so far are similar between females and males or if there exist any significant differences between constructs, we carried out multi-group analysis between female and male participants. Figure 3 shows the results of the path coefficient between constructs for the two groups and the significance or otherwise of these coefficients.

The personality types of males significantly influenced their continuance intention of shopping online compared to females which was insignificant. This suggests that the personality of a male shopper can influence his continuance intention of an e-commerce merchant, thus his shopping experience can be personalized based on his personality. This result was not what we expected as research has shown that women are socio-emotional and men are task oriented [3]. Thus, we expected women's personality to influence their continuance intention of ecommerce shopping since shopping is a social activity [10]. This was however not the case. One reason could be the demographics of participants in our data set. Research suggests that access to knowledge, education, culture and wealth are predictors of gender differences in personality [32]. Our data has more North American females compared to other cultures and almost equal number of male North American and Asian participants. This difference in culture could explain the difference in the magnitude of influence personality has on continuance intention based on gender. In the future, we plan to explore this line of thought by exploring if knowledge, education, culture and wealth have an influence on personality and continuance intention of e-commerce shoppers.

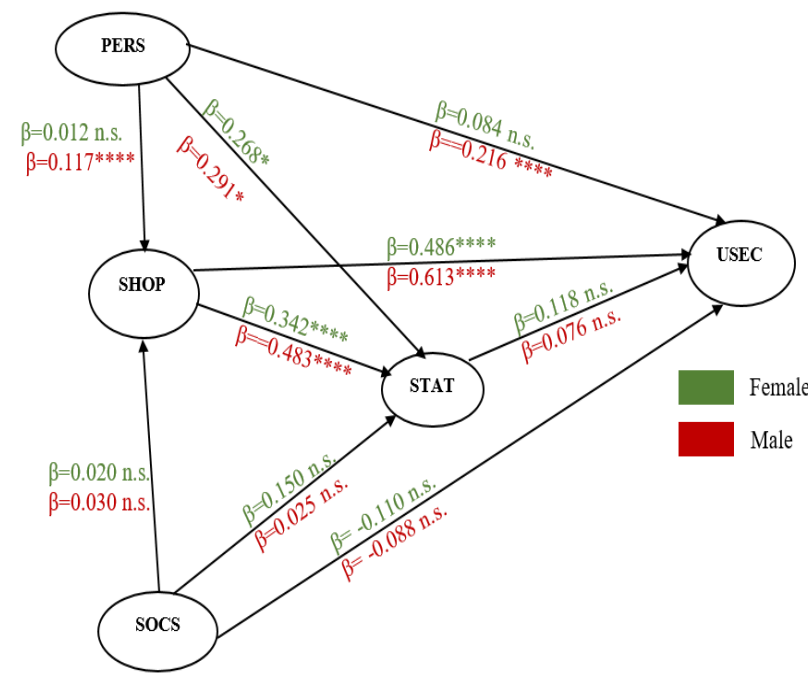

Figure 3. Path coefficient and significance between females and males. $P E R S=$ personality, $S H O P=$ shopper type, SOCS $=$ Social support, STAT $=$ Need for status, USEC $=$ Continuance intention. n.s. $=$ Not significant

Similar to the global model, the shopper type for both genders significantly influences the need for status and continuance intention of e-consumers. This further suggests the importance of understanding the shopper type of consumers and their susceptibility to products that show off their status in e-commerce personalization.

The implication to e-commerce developers and designers include the following:

1) The use of shopper type should be explored in the context of e-commerce personalization. For example, the e-commerce platform could be designed to identify the shopper type of the consumer. This can be done by identifying the motivation behind shoppers when they come online [30] or by observing their information seeking pattern when browsing or shopping for products [21].

2) The need for status should also be explored in the context of e-commerce personalization. The need for status describes consumers' desire for products because of their symbolic and social value and not the utility derived from these products [22]. The need for status can be measured by observing the purchase history of consumers in order to identify any history or pattern of purchasing "status" products.

3) Gender should be considered when personalizing consumers' shopping experience in 


\section{Ifeoma Adaji • Kiemute Oyibo • Julita Vassileva}

e-commerce as our results show significant differences between males and females. This is in line with other researchers who have explored the role of gender in personalization [27].

4) When personalizing shoppers' experience based on the shopper's gender, their personality can play an important role. Our results show that the personality of shoppers influence use continuance differently for females and males. Thus, being able to identify the gender of a shopper could be beneficial to the e-business. Similarly, being able to identify the personality of the shoppers can be of beneficial in personalization because personality has a significant influence on use continuance intention.

There are a few limitations to our study. First, the answers to the survey questions are self-reported by the participants and not based on observation. This is however common practice in the research community [29], [1]. Second, the number of participants we recruited for the study represents a small fraction of e-commerce shoppers. We are still recruiting participants; we intend to repeat this study on a larger scale to validate our findings from the current study.

In the future, we plan to explore the individual effects of the lower-order components (described in section 3.2) on the other constructs. For example, we plan to examine which of the personality types (openness to experience, conscientiousness, extraversion, agreeableness and neuroticism) has an influence on need for status and the continuance intention of e-commerce shoppers based on gender. The strength of this study is that there is currently no research that explores the need for status and shopper type in the context of e-commerce along with the personality and social status of the shoppers

\section{CONCLUSION}

The increase in the number of e-commerce businesses has led to the need for companies to develop more personalized shopping experiences for their clients. To contribute to ongoing research in this area, we explore the use of personality, shopper type, social support and need for status in e-commerce personalization and continuance intention of e-shoppers. Using a sample size of 226 e-commerce shoppers, we develop and test a global research model using partial least-squares structural equation modelling (PLS-SEM) analysis. Our results show that personality, shopper type, social support and need for status explain almost $60 \%$ of the variance in the continuance of users to shop online. This suggests that personality, shopper type, social support and need for status are good predictors of e-commerce continuance. In addition, shopper type has the strongest effect on continuance intention compared to personality, need for status and social support. This suggests the significance of identifying the shopping motivation and behaviour of consumers in ecommerce. To determine if these results were similar based on gender, we carried out multi-group analysis between males and females. There was a significant difference of the influence of personality on continuance intention of both genders, with males having a more significant effect. These findings suggest possible design guidelines in developing personalized e-commerce shopping experience for consumers.

\section{REFERENCES}

[1] Adaji, I. and Vassileva, J. 2017. Perceived Effectiveness, Credibility and Continuance Intention in E-commerce. A Study of Amazon. Proceedings of 12th International Conference on Persuasive Technology (Amsterdam, 2017).

[2] Ajzen, I. 2005. Attitudes, personality, and behavior. McGraw-Hill Education (UK).

[3] Aries, E. 1976. Interaction Patterns and Themes of Male, Female, and Mixed Groups. Small Group Behavior. 7, 1 (Feb. 1976), 7-18. DOI:https://doi.org/ 10.1177/104649647600700102.

[4] Barkhi, R. and Wallace, L. 2007. The impact of personality type on purchasing decisions in virtual stores. Information Technology and Management. 8, 4 (Nov. 2007), 313330. DOI:https://doi.org/10.1007/s10799007-0021-y.

[5] Bhattacherjee, A. 2001. An empirical analysis of the antecedents of electronic commerce service continuance. Decision Support Systems. 32, 2 (2001), 201-214. DOI:https://doi.org/10.1016/S01679236(01)00111-7.

[6] Bucciol, A. et al. 2014. Social status and personality traits. Journal of Economic Psychology. 51, (Dec. 2014), 245-260. DOI:https://doi.org/10.1016/J.JOEP.2015.10 .002 .

[7] Chan, W.Y.Y. 2015. Consumers' repurchase intention of luxury goods: examining the relationship among status consumption, need for uniqueness, materialism and affective response. (2015).

[8] Chin, W. and Marcolin, B. 2003. A partial least squares latent variable modeling approach for measuring interaction effects: Results from a Monte Carlo simulation study and an electronic-mail. Information systems. (2003). 
[9] Clark, R. et al. 2007. Status consumption and role-relaxed consumption: A tale of two retail consumers. Journal of Retailing and Consumer Services. 14, 1 (Jan. 2007), 4559.

DOI:https://doi.org/10.1016/J.JRETCONSE R.2006.03.003.

[10] Compeau, L.D. et al. 2016. Expressing and defining self and relationships through everyday shopping experiences. Journal of Business Research. 69, 3 (Mar. 2016), 1035-1042.

DOI:https://doi.org/10.1016/J.JBUSRES.201 5.08.016.

[11] Cunningham, D. and Thach, L. 2008. Innovative e-commerce site design: a conceptual model to match consumer MBTI dimensions to website design. Journal of Internet. (2008).

[12] Eastman, J.K.K. et al. 1999. Status Consumption in Consumer Behavior: Scale Development and Validation. Journal of Marketing Theory and Practice. 7, 3 (Jul. 1999), 41-52.

DOI:https://doi.org/10.1080/10696679.1999. 11501839.

[13] Eastman, J.K.K. and Eastman, K.L.L. 2011. Perceptions of status consumption and the economy. Journal of Business \& Economics Research. 9, 7 (2011), 9.

[14] Goldberg, L.R. 1990. An alternative description of personality: the big-five factor structure. Journal of personality and social psychology. 59, 6 (1990), 1216.

[15] Goldsmith, R.E.E. et al. 2010. Status Consumption and Price Sensitivity. The Journal of Marketing Theory and Practice. 18, 4 (Sep. 2010), 323-338. DOI:https://doi.org/10.2753/MTP10696679180402.

[16] Goldsmith, R.E.E. and Clark, R.A.A. 2012. Materialism, Status Consumption, and Consumer Independence. The Journal of Social Psychology. 152, 1 (Jan. 2012), 4360.

DOI:https://doi.org/10.1080/00224545.2011. 555434.

[17] Gosling, S.D. et al. 2003. A very brief measure of the Big-Five personality domains. Journal of Research in Personality. 37, 6 (2003), 504-528. DOI:https://doi.org/10.1016/S00926566(03)00046-1.

[18] Hair Jr, J. et al. 2016. A primer on partial least squares structural equation modeling (PLS-SEM). Sage Publications.
[19] Huang, J. and Yang, Y. 2010. The relationship between personality traits and online shopping motivations. Social Behavior and Personality: an. (2010).

[20] John, O. and Srivastava, S. 1999. The Big Five trait taxonomy: History, measurement, and theoretical perspectives. of personality: Theory and research. (1999).

[21] Keng Kau, A. et al. 2003. Typology of online shoppers. Journal of Consumer Marketing. 20, 2 (Apr. 2003), 139-156.

DOI:https://doi.org/10.1108/0736376031046 4604.

[22] Latter, C. et al. 2010. The Roles of Consumers Need for Uniqueness and Status Consumption in Haute Couture Luxury Brands. Journal of Global Fashion Marketing. 1, 4 (Nov. 2010), 206-214. DOI:https://doi.org/10.1080/20932685.2010. 10593072.

[23] Liang, T.-P. et al. 2011. What Drives Social Commerce: The Role of Social Support and Relationship Quality. International Journal of Electronic Commerce. 16, 2 (Jan. 2011), 69-90. DOI:https://doi.org/10.2753/JEC10864415160204.

[24] Lumsden, J. and MacKay, L. 2006. How does personality affect trust in $\mathrm{B} 2 \mathrm{C}$ ecommerce? Proceedings of the 8th International Conference on Electronic Commerce (ICEC'2006) (2006).

[25] Moe, W. 2003. Buying, searching, or browsing: Differentiating between online shoppers using in-store navigational clickstream. Journal of consumer psychology. (2003).

[26] Oinas-Kukkonen, H. and Harjumaa, M. 2008. A systematic framework for designing and evaluating persuasive systems. Persuasive technology. Springer. 164-176.

[27] Orji, R. et al. Gender, age, and responsiveness to Cialdini's persuasion strategies. Springer.

[28] Orji, R. et al. 2017. Towards personalitydriven persuasive health games and gamified systems. Proceedings of SIGCHI Conference on. (2017).

[29] Orji, R. et al. 2017. Towards Personalitydriven Persuasive Health Games and Gamified Systems. Proceedings of the 2017 $\mathrm{CHI}$ Conference on Human Factors in Computing Systems - CHI' 17 (New York, New York, USA, 2017), 1015-1027. 
Ifeoma Adaji • Kiemute Oyibo • Julita Vassileva

[30] Rohm, A.J. and Swaminathan, V. 2004. A typology of online shoppers based on shopping motivations. Journal of Business Research. 57, 7 (2004), 748-757.

DOI:https://doi.org/10.1016/S01482963(02)00351-X.

[31] Sanchez, G. 2013. PLS path modeling with R. Berkeley: Trowchez Editions. (2013).

[32] Schmitt, D.P.P. et al. 2008. Why can't a man be more like a woman? Sex differences in Big Five personality traits across 55 cultures. Journal of Personality and Social Psychology. 94, 1 (2008), 168182. DOI:https://doi.org/10.1037/00223514.94.1.168.

[33] Wong, K. 2013. Partial least squares structural equation modeling (PLS-SEM) techniques using SmartPLS. Marketing Bulletin. 24, (2013).

[34] Wu, W.-Y. and Ke, C.-C. 2016. An Online Shopping Behavior Model Integrating Personality Traits, Perceived Risk, and Technology Acceptance. Social Behavior and Personality: an international journal. 44, 3 (Apr. 2016), 85-97.

DOI:https://doi.org/10.2224/sbp.2015.43.1.8 5.

[35] Zimet, G. et al. 1988. The multidimensional scale of perceived social support. Journal of personality. (1988).

[36] 2011. How to win online: Advanced personalization in e-commerce; An Oracle white paper. 